\title{
El populismo como lógica de acción política*
}

\author{
Filipe Carreira da Silva** \\ Mónica Brito Vieira***
}

\section{RESUMEN}

Este artículo ofrece una nueva perspectiva para entender el populismo. El argumento se desarrolla de la siguiente forma. En un primer momento, se pasa revista a la literatura populista y se identifican dos enfoques principales: uno óntico y otro orientado a la lógica, entre los que destaca la lógica de la enemistad planteada tanto por Schmitt como por Laclau. A pesar de que compartimos con Laclau la crítica a los enfoques ónticos, en este artículo no se comparte ni su comprensión ontológica de la enemistad, ni su doble aseveración entrelazada de que el populismo es toda la política y de que la enemistad es la lógica del populismo. En un siguiente momento, se localizan los orígenes del populismo en una paradoja dentro del corazón mismo de la democracia. Si bien la democracia se entiende como una comunidad de inclusión; al mismo tiempo, sin embargo, la exclusión es constitutiva de toda inclusión, asimismo, por tanto, de la inclusión democrática. Luego se discute lo que los autores consideran la verdadera lógica del populismo: el resentimiento. A diferencia de la enemistad -que funciona en la teoría laclauniana del populismo como una ontología de no-identidad-, el resentimiento opera en un marco de rivalidad, lo que presupone una identificación entre las partes y hace referencia a un conjunto de compromisos normativos. Finalmente, el artículo concluye presentando un entendimiento del populismo como una lógica específica de acción política.

\section{PALABRAS CLAVE}

democracia, movilización política, soberanía popular, populismo, resentimiento.

\footnotetext{
* Este artículo apareció primero en Carreira da Silva, F. \& Brito M. (2019) Populism as a logic of political action, European Journal of Social Theory. 22(4), 497-512. DOI: 10.1177/1368431018762540. La traducción estuvo a cargo de Sebastian Raza. Este trabajo es financiado por fondos nacionales a través de FCTFundación para la Ciencia y Tecnología, I.P., en el ambito del proyecto PDTC/SOC-SOC/28524/2017. ** Instituto de Ciencias Sociales, Universidad de Lisboa, Portugal; Selwyn College, Universidad de Cambridge, Reino Unido. Email: fcs23@ics.ulisboa.pt.

${ }^{\star \star \star}$ Universidad de York, Heslington, York, Reino Unido
} 


\begin{abstract}
This article offers a new understanding of populism. The argument unfolds as follows: first, the populist literature is reviewed, and two main approaches are identified: ontic and logic-oriented, the more important of which is the Schmitt-Laclau logic of enmity. While the authors broadly agree with Laclau's criticism of ontic approaches, they endorse neither his ontological understanding of enmity, nor his claim that populism is politics, and enmity is the logic of populism. Next, the origins of populism are located in a paradox at the heart of democracy. Democracy defines itself as a community of inclusion, yet exclusion is constitutive of inclusion, including therefore democratic inclusion. Then is discussed what the authors believe to be the true logic of populism: resentment. Unlike enmity, which functions in Laclau's populist theory as an ontology of non-identity, resentment operates within a rivalrous framework, which presupposes identification between the parts and refers to a set of normative commitments. Finally, the article concludes by presenting an understanding of populism as a specific logic of political action.
\end{abstract}

\title{
KEYWORDS
}

democracy, political mobilization, popular sovereignty, populism, resentment 


\section{Presentación del problema}

Q1 término populismo está en boga. Ahora bien, con cada nuevo uso, la categoría de populismo pareciera ser más confusa. Para algunos, el populismo es némesis de la democracia. Para otros, es la única esperanza para una redención democrática en una era de rampante inequidad y globalización económica. Mientras que unos enfatizan el carácter camaleónico del populismo, otros buscan asignarle una naturaleza extremadamente fija. Aunque a menudo se reduce a un estilo específico de comunicación política que se mueve rápidamente de los márgenes al mainstream de la democracia política, el populismo muchas veces se identifica con cierta forma de movilización política o, en sentido amplio, con una orientación anti-élites. Al tiempo que algunos lo consideran una política peligrosa, otros lo entienden como la política misma. Pero ¿es el populismo realmente tan ubicuo? ¿O estamos estirando el concepto tan indiscriminadamente al punto de perder su utilidad? Para restituir su utilidad $-\mathrm{y}$, por tanto, para ampliar nuestra comprensión de la realidad que describe, informa y evalúa-, este artículo ofrece una articulación alternativa a las comprensiones principales y bien conocidas del concepto de populismo.

Nuestro argumento se desarrolla de la siguiente manera. En la siguiente sección, se revisa la literatura populista y se identifican dos enfoques: el óntico y el orientado a la lógica, entre los que destaca la lógica de la enemistad planteada por Schmitt y por Laclau. A pesar de estar de acuerdo con Laclau en la crítica a los enfoques ónticos, nosotros no compartimos ni su comprensión ontológica de la enemistad, ni su doble aseveración entrelazada que plantea que el populismo es toda la política y que la enemistad es la lógica del populismo.

En la siguiente sección, localizamos los orígenes del populismo en una paradoja dentro del corazón mismo de la democracia. La democracia se 
entiende como una comunidad de inclusión; al mismo tiempo, sin embargo, la exclusión es constitutiva de toda inclusión, y asimismo de la inclusión democrática. El populismo, argumentamos, emerge de esta paradoja y, en particular, del malestar generado por la percepción de un incumplimiento de las promesas de inclusión democráticas. Como resultado, un segmento del pueblo se vuelca en contra de otro en el nombre de la reconstitución de un pueblo igualitario imaginado, que es considerado la base de legitimidad de la autoridad política. Inmediatamente, discutimos lo que consideramos la verdadera lógica del populismo: el resentimiento. A diferencia de la enemistad, que funciona en la teoría laclauniana del populismo como una ontología de no-identidad, el resentimiento opera en un marco de rivalidad, lo que presupone una identificación entre las partes y hace referencia a un conjunto de compromisos normativos. No obstante, el resentimiento no es un fenómeno unitario. Su diversidad interna es importante para entender dónde el populismo empieza y dónde termina. Finalmente, concluimos presentando un entendimiento del populismo como una lógica específica de acción política.

\section{Enfoques existentes acerca del populismo}

Es de considerable dificultad definir el populismo. Al ser una palabra que ha devenido en un término peyorativo, muy pocos actores políticos se llamarían a sí mismos populistas. En la literatura sobre casos empíricos, los populismos forman una colección ecléctica de movimientos, partidos y líderes políticos, que van desde el narodnichestvo ruso y los populistas norteamericanos del siglo XIX a los populismos carismáticos latinoamericanos de Juan Perón y Getulio Vargas de la década de los 50, la ola neopopulista de los 90 en Europa y su más reciente resurgimiento tanto 
en Europa como en Estados Unidos (ejemplificados por el Partido de la Libertad de Austria de Jog Haider y por la presidencia de Donald Trump). Los enfoques utilizados para estudiarlos son tan disímiles como los casos empíricos. Estos varían en diversos aspectos: en su grado de abstracción o generalidad, su objetivo o función principal, o su metodología privilegiada. En la mayoría de los casos, estas diferencias pueden rastrearse en sus fundamentos epistemológicos.

Estos, a su vez, pueden ser divididos en dos categorías. Por una parte, hay enfoques ónticos que conciben a la realidad material, factual y física independientemente de nuestro conocimiento de ella. Aquí se aglutinan, por un lado, enfoques empírico-deductivos orientados a explicar el populismo mediante el descubrimiento de relaciones causales entre determinantes estructurales y sus consecuencias populistas; y, por otro lado, enfoques hermenéuticos cuyo objetivo es producir descripciones densas del populismo mediante casos de estudios históricamente detallados. A pesar de sus diferencias, tanto los enfoques empírico-deductivos como los enfoques hermenéuticos se orientan a los contenidos - y no a la lógica-del populismo.

En 1969, Peter Wiles, en su ensayo 'Un síndrome, no una doctrina: algunas tesis elementales sobre populismo', ofrece un buen ejemplo de un enfoque empírico-deductivo. Wiles asume la existencia de un genus populista, de una esencia definitoria, que se identifica ideográficamente, es decir, mediante el estudio de sus manifestaciones históricas concretas. A partir de esto, se inducen un número variable de criterios generalizables (en su caso, no menos de 24) y se formula una definición 'descriptivamente útil' de populismo, en palabras de Wiles, 'de modo que coincide con las divisiones naturales del mundo real' (1974 [1969]: 171).

Consciente de las limitaciones de los enfoques anteriores, como el de Wiles, Margaret Canovan (1981:12), en su libro Populism, recurre a una estrategia inspirada en la hermenéutica para la formación de conceptos. 
La autora emplea una distinción analítica entre populismos 'agrarios' y 'políticos' con el objetivo de proponer una tipología de populismos, en la que cada grupo se subdivide posteriormente hasta formar un total de siete tipos de populismos (1981: 13). Esta distinción analítica resulta, sin embargo, insuficiente en la medida en que ejemplos concretos y reales trascienden varias categorías, dejándonos en último término en el mismo lugar al que Wiles había arribado 12 años atrás.

Los intentos no exitosos de Wiles y de Canovan por delimitar el populismo como una categoría óntica poco contribuyeron para prevenir a la mayoría de literatura posterior de seguir sus pasos. En consecuencia, queda mucha confusión acerca de qué cosa es el populismo, y acerca de en qué debemos reparar cuando lo estudiamos: ¿debemos tomarlo como una estrategia o modo de organización (Weyland, [2001] (2004): 14; Betz, 2002: 198), como un proyecto o repertorio de movilización política (Jansen, 2011: 82; Brubaker, 2017: 4-6), como una ideología (Canovan, 2002; 2004; Mudde, 2004; 2007), como un modo de persuasión (Kanzin, 1995), como un discurso (ver, por ejemplo, Torfing, 1995; Howarth y Stavrakakis, 2000; Pauwels, 2011), o simplemente como un estilo de comunicación política (por ejemplo, Moffitt y Tormey, 2014)? Como resultado de esta situación, la pregunta de 'si el populismo es esencialmente un proyecto de izquierda o de derecha, fascista o igualitario, progresista y con vistas al futuro o nostálgico y con vistas al pasado' (Minogue, 1974 [1969]: 200) emerge repetidamente y no encuentra respuesta alguna. Nunca se llega a una clara delimitación del populismo en tanto concepto ni en tanto fenómeno. Lo único que queda es un impasse intelectual, puesto que, aunque el populismo podría definirse como estrategia, ideología, discurso o estilo, no hay duda de que el término no puede ser todo eso al mismo tiempo. En la medida en que movimientos populistas con distintas bases sociales, estrategias organizacionales y orientaciones ideológicas coexisten sincrónicamente o se suceden en el tiempo, necesariamente se genera una confusión generalizada. 
Las alternativas a los enfoques ónticos son aquellas que apuntan a identificar la estructura y/o lógica según la cual los contenidos se organizan. El trabajo tardío de Canovan (1999) y La Razón Populista de Ernesto Laclau (2005) son ilustraciones de este tipo de enfoque. En sus análisis del populismo, Canovan (1999: 3) se alejó de la hermenéutica para acercarse al estructuralismo: 'desviamos nuestra atención de la ideología y de los contenidos políticos de los movimientos populistas' —afirma la autora- ' $\mathrm{y}$ nos concentramos en su lugar en consideraciones estructurales'. Por consideraciones estructurales, Canovan se refiere a tres características fundamentales que considera que comparten todas las formas políticas populistas: (1) anti-elitismo; (2) una referencia al 'pueblo'; y (3) un estilo simple y directo. De este modo, tal como queda en evidencia, el enfoque de Canovan es, al fin y al cabo, parcialmente mixto; así como también lo es más recientemente el enfoque de Cas Mudde. A pesar de su definición óntica del populismo como una 'ideología' coherente, sin importar cuán 'mínima' sea, Mudde (2004) se orienta hacia una dirección estructural el momento en que trata al populismo como una visión particular acerca de cómo está estructurada y debería estructurarse la sociedad. El autor continúa en esta dirección al identificar en el populismo un fenómeno que establece un marco sin contenidos específicos —el antagonismo entre el pueblo y las élites en el contexto de la soberanía popular. El reconocimiento de la indeterminación fundamental del populismo va de la mano con un distanciamiento de cualquier enfoque óntico más 'denso', que defina al populismo como demagogia, liderazgo carismático o discurso político simplista (Mudde, 2004). En efecto, dadas las dificultades encontradas por enfoques ónticos o por enfoques orientados a la lógica, varios autores han intentado abiertamente buscar un punto medio e integrar ambas dimensiones en sus trabajos (ver, por ejemplo, Canovan, 2002; Arditi (2010 [2007])). Esto ha llevado a los llamados 'nuevos estudios populistas', por ejemplo, a desplazar su centro de atención 'de los contenidos sociales del populismo y 
los fines que persigue a los medios que emplea para conseguirlos' (Jansen, 2011: 82); a estudiar por qué las crisis económicas necesitan de acciones 'performativas' de agentes sociales para devenir en causas efectivas para políticas populistas (Moffitt, 2015); a examinar cómo los contenidos del populismo parecerían estar organizados por 'marcos discursivos' (Aslanidis, 2015), y a analizar cómo la formación de reivindicaciones populistas sigue un guion y envuelve tropos retóricos específicos (Bonikowski y Gidron, 2014). Sin embargo, tomando en cuenta la difusión del modo de hacer política llamado populista, este enfoque en los medios ha sido incapaz de esclarecer lo distintivo del populismo, o incluso de dar una respuesta esclarecedora sobre si es distintivo en lo absoluto.

Contra la preminencia de enfoques mixtos, el trabajo de Ernesto Laclau, del cual nos ocuparemos ahora, se destaca por abordar el populismo desde un enfoque estrictamente orientado a la lógica. Para Laclau (2005), el populismo se origina en una lógica fundamental: una 'lógica oposicional' dirigida a construir un sujeto político unificado ('el pueblo') a partir de un conjunto disperso y dispar de agravios o injusticias que se definen contra el poder dominante de una élite corrupta. La 'lógica oposicional' de Laclau tiene un antecesor claro: la lógica de la enemistad que Carl Schmitt (1991 [1927]) declaró como integral para la comprensión de lo político y para su crítica al liberalismo. Hasta la actualidad, aun a pesar de no ser reconocida recurrentemente, la concepción distintivamente schmittiana del populismo sigue siendo dominante y ampliamente empleada en la literatura. Esta concepción se fundamenta en la afirmación de Schmitt de que la lógica abstracta de la democracia gira alrededor de una serie de identidades (por ejemplo, entre gobernados y gobernantes, soberano y sujeto, voluntad y ley, etc.). Así, más que ser realidades tangibles, estas identidades se interpretan política y simbólicamente. Su naturaleza es la de las identificaciones que dependen de obtener el reconocimiento de aquellos que deben identificarse con ellas. El proceso de identificación se vuelve más efectivo mediante 
la abolición o elusión de cualquier mediación, como, por ejemplo, de procedimientos formales, contrapoderes, e instituciones que definen al Estado Constitucional. A medida que las mediaciones son abolidas, el clamor popular de la voluntad del pueblo-como-uno ocurre sin obstáculo alguno. La voluntad del pueblo, tal como muchas veces es enunciada por una minoría o, incluso, por un orador singular, se inviste así de una inmediatez (ilusoria) y presencia absoluta, cuya producción depende vitalmente de la lógica de la enemistad. Esta visión schmittiana del populismo lo ubica como gemelo siamés de la democracia. Su perdurable influencia puede comprobarse en los extremos opuestos del espectro político, a saber: tanto entre demócratas radicales que la apoyan (por ejemplo, Laclau), como entre críticos liberales que la rechazan dado que la perciben como elemento subversivo de la democracia (Abts y Rummen, 2007; Urbinati, 2014; o hasta Müller, 2016, por ejemplo). Esto incita a que se inspeccione su lógica subyacente a mayor profundidad.

En El Concepto de lo Político, publicado por primera vez en 1927, Schmitt presenta la distinción amigo-enemigo, 'aquella [distinción] a la que pueden reconducirse todas las acciones y motivos políticos' (Schmitt, 1991 [1927]: 56). El centro de atención de Schmitt está en la figura del enemigo, que retrata como 'el otro, el extraño, y para determinar su esencia basta con que sea existencialmente distinto y extraño en un sentido particularmente intensivo' (Schmitt, 1991 [1927]: 57). La emergencia del pueblo como una presencia evidente en sí misma depende de-y se mantiene gracias a- esta división antagonista entre sí y este otro.

En sus escritos sobre política como hegemonía (Laclau y Mouffe, 1987), así como en su aplicación al populismo, Laclau se inspira fuertemente en esta idea de Schmitt. Su forma de tratar la enemistad difiere, no obstante, en un aspecto crucial. Mientras que, en Schmitt, la enemistad conduce a una concepción völkisch del populismo; en Laclau, el 'pueblo' y el 'enemigo' se conciben como significantes vacíos, cuya inestabilidad permite incesantes 
disputas y redefiniciones. Esto se debe a que Laclau, bajo la influencia de la semiótica, prescinde absolutamente de los contenidos. En su trabajo, por tanto, el populismo se convierte en una cuestión de pura lógica: 'su significado no debe hallarse en ningún contenido político o ideológico que entraría en la descripción de las prácticas de cualquier grupo específico', observa Laclau (2009 [2005]: 53), 'sino en un determinado modo de articulación de esos contenidos sociales, políticos o ideológicos'. Como resultado, el populismo se entiende como inmanente a la política misma, como una lógica inherente a la experiencia social y política.

Esta no es, sin embargo, una lógica en sentido epistémico, sino una lógica que opera a un nivel más profundo y fundamental: el antagonismo es para Laclau una ontología de la identidad política. La identidad implica negación porque la presencia del otro es intrínsecamente una amenaza para mí. La identidad es, por lo tanto, un concepto relacional, siempre fundado en la diferencia, y nunca completa. Así, el antagonismo, la lucha y el conflicto son inevitables en la política. La totalidad de la sociedad nunca puede ser representada por actor político alguno. Esta, en última instancia, elude la representación. Por el contrario, la sociedad se funda en objetos discursivos imposibles, tal como 'el pueblo', que representa el todo en su ausencia. La unidad de este 'pueblo' es una representación no una cosa en sí misma, y mucho menos una cosa que preexista a su propia representación- que en todo momento presupone una división constitutiva entre un yo y un otro. Esto efectivamente constituye el caso paradigmático de representación política, según el cual el representante crea la propia autoridad que presupone al encarar su (imposible) unidad simbólica. En otras palabras, al actuar desde un terreno social en disputa entre intereses y demandas en competencia, el representante articula al ‘pueblo' como una autoridad política unificadora al tiempo que legitima su propia acción apelando a la voluntad autorizante de esa autoridad recién articulada (Laclau, 2005: 206). Esto significa también que 'el pueblo' se 
vuelve la lógica que estructura lo político, es decir, que toda la política es populista (Laclau, 2005: 192) y que 'el pueblo' es un significante vacío, que logra vincular distintas luchas en una cadena de equivalencias y que es desplegado para promover proyectos políticos particulares. Cuando la gente ordinaria se concibe a sí mismos como populus, como la parte que representa al todo, se construye un 'pueblo' en el marco de la estructura del lenguaje y su sistema abstracto de contrastes. En este sentido específico, los modos en que 'el pueblo' se constituye son estrictamente arbitrarios: no se hace referencia a nada que esté más allá de la estructura del lenguaje mismo.

Sin embargo, la pregunta sigue siendo si Laclau está en lo correcto al afirmar que toda política es populista y que la razón o lógica populista es fundamentalmente aquella del enemigo. Nosotros sostenemos que Laclau está equivocado en ambas afirmaciones por dos razones fundamentales. En primer lugar, tanto para Schmitt como para Laclau, la enemistad no es solo la lógica del populismo, sino de la política misma. No obstante, si se considera que la enemistad es ubicua en el dominio de lo político — desde soluciones democráticas a soluciones no-democráticas de diversos matices ideológicos-, entonces ¿qué es exactamente lo específico del populismo? En segundo lugar, de acuerdo con esta lógica, el 'amigo' se enfrenta con una entidad que es, en palabras de Schmitt, 'existencialmente distinta y extraña'. Esto es compatible con la idea muy repetida de que lo distintivo del populismo es la evocación de una imagen unificada y homogénea del pueblo. Al mismo tiempo, esto significa que el populismo implica un rechazo radical a todo lo que considera hostil para tal unidad y homogeneidad: extranjeros, enemigos, oligarquía, élites (Rosanvallon, 2007). Pero, a pesar de la severidad de los procesos de exclusión y construcción de otredades que afligen a las democracias liberales que afrontan estallidos populistas especialmente aquellos de tendencia de derecha- - pese a que afirmaciones del tipo 'nosotros somos el 99\%' —en las que el 'nosotros' es un 'nosotros, 
el pueblo' - pueden efectivamente excluir al $1 \%$, existe una complejidad en las afirmaciones populistas que la tesis de la enemistad ignora. El 99\% sigue siendo el $99 \%$ de un todo, que es a fin de cuentas el 100\%. En otras palabras, la división se mantiene principalmente dentro del pueblo, o entre conciudadanos, en lugar de entre el pueblo y un exterior radical. El 'pueblo' continúa siendo en este caso una comunidad política vinculada por ciertas normas, procedimientos y valores, sin importar cuán disputados o traicionados sean. Persiste, del mismo modo, como el fundamento de la legitimidad de la autoridad política: de ahí la típica estructura de las demandas populistas como reivindicaciones de una parte enunciadas en el nombre del todo ('el pueblo') que podría autorizar y conferir legitimidad. El conflicto que opone a la mayoría (el sujeto popular) a los pocos (o las élites), o incluso el enfrentamiento de partes dentro de la mayoría — como sucede, por ejemplo, con las partes silenciosas o no escuchadas contra las partes con voz o escuchadas-, no opone a enemigos mortales, sino a rivales y competidores. El populismo, argüimos, no es un sinónimo de la política misma, sino un brote de la soberanía popular y su promesa igualitaria. $\mathrm{Su}$ lógica primaria no es una lógica oposicional de amigo-enemigo, sino una lógica de resentimiento entre conciudadanos.

\section{Los orígenes del populismo: la paradoja democrática}

Mientras que Laclau argumenta que la lógica del populismo es clave para entender la política como tal, nosotros argumentamos que el populismo es una consecuencia de la democracia y que su lógica no puede ser entendida independientemente del compromiso fundamental de la democracia con el principio de igualdad. En palabras más simples, el populismo es el resultado de una paradoja en el corazón de la democracia. Un impulso hacia 
la inclusión universal se inscribe en el proyecto democrático. Sin embargo, sucede que la exclusión es constitutiva de la inclusión. La exclusión es por tanto inevitable. Con cada intento de ampliar la inclusión, nuevas formas de exclusión emergen. Sin importar lo mucho que la democracia intente disolver las líneas divisorias, nuevas divisiones continúan surgiendo. Basta ver, a modo de ejemplo, cómo el principio de inclusión democrática de todos los sujetos a la ley evoluciona naturalmente hacia la inclusión de todos los afectados por ella; pero entonces choca con la existencia de fronteras, definiendo así comunidades de solidaridad cerradas. O, consideremos, por ejemplo, cómo, en una democracia constitucional, los derechos tienen una dinámica inherente hacia la inclusión universal, pero muy a menudo se mantienen reservados solo para los ciudadanos, e incluso para algunos de ellos están fuera de alcance a nivel informal. Las exclusiones que afectan a los no-ciudadanos, por no mencionar aquellas que afectan a los ciudadanos, son especialmente desestabilizadoras en democracias, dado que son antagónicas a la comprensión de la estas como una comunidad inclusiva, construida sobre relaciones perfectamente simétricas, que gira alrededor del reconocimiento de la libertad universal y la igualdad. Al ser constitutiva de la inclusión, la exclusión es ineludible; pero las exclusiones concretas no necesariamente lo son. Debido a su enraizamiento normativo en el principio de igualdad entre individuos, las democracias son el régimen en el que tales exclusiones se tornan más intolerables y su carácter contingente se visibiliza más y más. Por ejemplo, este es el caso especialmente en tiempos, como los actuales, de creciente desigualdad económica. La promesa democrática cardinal de igualdad de condiciones y oportunidades sigue siendo simplemente eso: un ideal al que se aspira, pero a menudo demasiado distante como para tener repercusiones prácticas. Las causas y consecuencias políticas de esta escalada se vuelven de igual manera más evidentes. El compromiso normativo e institucional de la democracia moderna con la igualdad generalizada sucumbe ante las 
claras evidencias de la profundización de las desigualdades ya existentes de influencia política sobre el sistema político, el cual podría mitigarlas o, en el mejor de los casos, contrarrestarlas (Bartels, 2008).

El que la democracia esté fundamentalmente orientada hacia la inclusión es difícil de negar. Democracia significa literalmente 'el gobierno del pueblo' o 'el poder de los ciudadanos'. Las democracias modernas intentan combinar este legado con la idea liberal de que el poder debe mantenerse como un lugar vacío (Lefort, 1998: 17). Esto significa que 'el pueblo' no es una unidad, sino, en el mejor de los casos, un todo compuesto por partes en disputa; $y$, en definitiva, cualquiera de estas partes puede ocupar el puesto del poder únicamente de forma temporal. Como resultado, el conflicto nunca desaparece pese a que está institucionalizado. Al mantener el poder como un lugar vacío para ser ocupado por aquellos que vienen ante el pueblo y profesan representar y encarnar su voluntad, las democracias liberales han pervivido bajo la sospecha de no ser más que una maquinaria opaca operada por - $\mathrm{y}$ en beneficio de la circulación y reproducción de - las élites (ver, por ejemplo, Laclau, 2005: 207-16). Su promesa es incluir, a través de la representación, aquello que excluye (al menos directamente, del gobierno). La promesa sigue siendo que, si bien no podemos exactamente gobernar, no estamos simplemente gobernados, dado que seguimos siendo soberanos en tanto supervisamos y somos los jueces supremos del gobierno. No obstante, esta es una promesa que a menudo nos parece falsa (Garsten, 2012).

En particular, la promesa de tener 'voz' es de suma importancia en un régimen en el cual se supone que todos tienen participación y 'voto' en la política, aun cuando a veces sea solo para expresar (des)confianza en aquellos que gobiernan. La participación ciudadana en condiciones de igualdad (formal y sustantiva o material) constituye el baluarte a partir del cual se organizan las instituciones políticas de la democracia liberal. Los datos disponibles acerca de la inclusión democrática como el goce 
de derechos ciudadanos —incluyendo los varios casos de participación política- muestran que esto no es un mero 'discurso de los derechos' (Kaase, 2007: 786-91). Aquellos que pertenecen de jure a las democracias liberales modernas disfrutan de hecho de niveles sin precedentes de 'voz y voto' en la conducción colectiva de la vida cívica. Sin embargo, la 'voz' puede estar distribuida de modo asimétrico, con algunas voces que se encuentran desproporcionadamente amplificadas, mientras que otras se silencian y relegan a la periferia de los círculos de poder. La condición de ciudadanía silenciosa, por la cual uno se siente privado de una voz efectiva en procesos democráticos, es bastante común en las democracias modernas (Gest y Gray, 2015; Green, 2015). Donde sea que este silencio logre perpetuarse, se pueden reflejar déficits democráticos significativos, o la exclusión de ciertos grupos de los círculos de influencia, en el proceso de formación de voluntad y de toma de decisiones. El silencio no implica necesariamente, en este caso, falta de habla, sino el rechazo a reconocer como válidos - o la incapacidad de escuchar - modos de habla localizados en diferentes modos - lo cual muchas veces encuentra refuerzo en la teoría política. Por ejemplo, el influyente ideal habermasiano de una esfera pública política como arena de inclusión racional ha sido ampliamente denunciado como un mito que perpetúa las condiciones excluyentes de todos aquellos que no forman parte de ella (Fraser, 1999 [1990]). Asimismo, termina por reflejar (en lugar de cuestionar) las definiciones hegemónicas de quién debe hablar y de qué debe ser escuchado. No es extraño que diferentes formas de exclusión (basadas en raza, etnia, género, clase, etc.) se intersequen en la trayectoria de vida de individuos concretos, intensificando así el sentimiento y la realidad de la exclusión. A nivel colectivo, trayectorias de clase descendientes pueden entrelazarse con identidades étnicas y de género, alimentando así el apoyo a candidatos y fuerzas políticas marginales, y dando lugar al surgimiento de orientaciones 'nacionalistas llenas de resentimiento' (Fenton, 2012). Este es el caso, 
entre otros, de la 'clase trabajadora blanca' en Estados Unidos y Reino Unido que, otrora el centro de sus sociedades y política nacional, hoy en día se encuentra cargada de ira por la pérdida de status en la jerarquía social de su comunidad y por la inhabilidad de los partidos políticos tradicionales para escuchar adecuadamente sus puntos de vista durante los procesos de formulación de políticas públicas (Gest, 2016).

La paradoja que afecta a la democracia - definida como una comunidad inclusiva sostenida por fuertes compromisos igualitarios implica que la exclusión, sobre todo cuando es percibida como unilateral y sistémica, es un problema que socava la legitimidad de esta forma de gobierno de una manera particularmente aguda. En ninguna parte la distancia entre la promesa de inclusión y la realidad de exclusión se siente con más fuerza que en un sistema cuya validez y facticidad —es decir, sus fundamentos normativos, procedimientos e institucionesestán explícitamente orientadas a la inclusión; y cuya 'psicología' incluye cuestiones como una sospecha del poder y la jerarquía, además de un sentimiento de desconfianza de los representantes. Las formas de gobierno no democráticas no están orientadas hacia la inclusión. La legitimidad en las dictaduras proviene de un vasto rango de fuentes alternativas que van desde la autoridad teológica o la tradición comunal hasta la fuerza militar y el crecimiento económico. Gracias al umbral más bajo de inclusión y de principios de cohesión, que también sirve como justificación para formas (parciales) de exclusión (por ejemplo, apuntando a compensaciones entre libertades civiles y políticas, y estabilidad y crecimiento económico), las formas de gobierno no democráticas generan y coexisten junto con exclusiones que a menudo pasan desapercibidas y son toleradas estoicamente. Mas, en el caso de la democracia es menos probable que esto ocurra. Situaciones subjetivas de privación (entendidas aquí como una cuestión ligada al logro económico, político y social), o a la discrepancia 
entre expectativas y cumplimiento esperado o percibido (mediante una disminución de movilidad social), crean una gran oportunidad para una política del resentimiento (Gest, 2016).

\section{La(s) lógica(s) del resentimiento}

La asociación de populismo y resentimiento ya ha sido enunciada antes (ver, por ejemplo, Shils, 1956; Barbalet, 1992; Mudde, 2004: 547; Cramer, 2016; Engels, 2015; Müller, 2016: 88). Pese a su claridad, los análisis anteriores emplean el concepto de resentimiento sin desarrollarlo con precisión abstracta, sino infiriendo su sentido de manifestaciones concretas (por ejemplo, Cramer, 2016); o lo toman como una emoción propensa a la manipulación retórica (por ejemplo, Engels, 2015). Este artículo difiere de enfoques previos en tanto sostiene que el populismo es ante todo una lógica, y que la lógica del populismo es el resentimiento. Al tomar al resentimiento como una lógica y no como una emoción, no se niega que este sea en efecto una emoción con atributos cognitivos y afectivos (ver, por ejemplo, Demertzis, 2006: 114ss, acerca de cómo los sentimientos de resentimiento inspiran la fase inicial de la movilización populista). A lo que apuntamos es a poner atención a la lógica de esta emoción. Por 'lógica' no debe entenderse en este caso como un sistema formal de inferencia, ni tampoco en el sentido laclauniano de 'gramática especial que rige cada esfera de la actividad humana' (Laclau, 1999: 102). Nuestro proyecto es muy distinto en sus supuestos y afirmaciones implícitas. Nos alejamos de la postura de Laclau según la cual la enemistad es una característica (onto-)lógica de toda la política — por tanto, también del populismo-, y nos movemos hacia la afirmación, mucho más específica y limitada, de que, pese a todas sus redefiniciones en el cambiante contexto de la historia, 
el populismo tiene ciertas características necesarias que pueden someterse a un análisis lógico. Más precisamente, afirmamos que el populismo se mueve de acuerdo con una lógica del resentimiento, que opera dentro de, y se moviliza por, los compromisos igualitarios de la democracia. Esta lógica —defendemos - configura en gran medida 'los objetos que es posible constituir' y 'las relaciones posibles entre estos objetos' (Laclau, 1999: 102), sin llegar a determinarlos del todo. No obstante, esta lógica proporciona fundamentos suficientes para distinguir ciertos fenómenos como populistas.

Para profundizar más en la lógica del resentimiento, es necesario regresar donde todo comienza. El Libro 2 de la Retórica de Aristóteles inicia con una larga discusión acerca de la ira (orgēe), que, junto a 'la vejación y la calumnia' son 'las causas que producen enemistad (ekhthra)'. Pero, mientras que 'el uno [ira] es con pena [para quien siente la ira], lo otro [el odio] sin ella'. Esto porque, explica Aristóteles, 'el uno desea que se las pague aquel contra el que está airado, el otro, que no exista [la clase de personas por las que se siente odio]' (Aristóteles, 1971: 106-7). En otras palabras, la ira, en contraste del odio -que, al igual que la enemistad, implica negación y, por tanto, la exclusión de algo-, necesita que el otro continúe existiendo, de tal manera que se pueda infligirle sufrimiento y universalizarlo.

Hacia el final del Libro 2, Aristóteles dirige su atención hacia un subconjunto de emociones dirigidas hacia personas que no son amigos cercanos o enemigos. En oposición a la ira y al odio, estas emociones se orientan hacia la fortuna de los otros. Son emociones de rivalidad o de competencia en la medida en que se centran en el pesar o malestar causados en nosotros predominantemente por la posesión de otros de bienes, como la riqueza, el poder o la ocupación de puestos oficiales. Las tres emociones consideras son la indignación (nemesis), la envidia (phthonos) y la emulación (zēlos), que en conjunto producen resentimiento (Aristóteles, 1971: 131ss). 
Es en este sentido que vale la pena realizar un examen minucioso de estas emociones. Las distinciones a partir de las cuales Aristóteles clasifica estas emociones se relacionan con las razones por las que uno se resiente de los bienes de otro. En el caso de la emulación, esto se da porque uno los desea para uno mismo. Según la definición de Aristóteles (1971: 124), 'es un pesar al mostrarse presentes bienes estimados susceptibles de ser alcanzados por uno, contra los que son de natural semejante, y no porque pertenecen a otro, sino porque no a uno'.

En el caso de la indignación, esta se da porque los bienes han sido adquiridos injustamente. En el caso de la envidia, por simple malicia. De la discusión de Aristóteles se llega a que la operación de la lógica del resentimiento, en la que se subsumen las tres emociones, supone que los dos agentes involucrados sean partes de un mismo juego (ver Geuss, 2016: 170ss). Si este es obviamente el caso con la emulación y la indignación — donde las partes se siguen entendiendo como compañeros morales que comparten un marco normativo común-, Aristóteles aclara que incluso en el caso de la envidia se requiere algún tipo de identificación, ya que solamente envidiamos a aquellos a los que consideramos ser "como nosotros’ en algún aspecto. Según Aristóteles (1971: 121):

se sentirá envidia contra los que son a uno iguales o lo parecen. Llamo iguales a los en estirpe o parentela, en edades y en hábitos, en fama y fortuna, [al igual que aquellos que no logran tener todos estos atributos en igualdad de condiciones]. ${ }^{2}$

Por tanto, si las masas de ciudadanos atenienses envidian a los aristócratas que gobiernan, esto se da porque, a pesar de sus diferencias en términos de riqueza y poder, ellos de todos modos los conciben o ven como sus

\footnotetext{
2 [N.T.] Lo introducido en paréntesis no consta en la traducción castellana de la Retórica de Aristóteles. He traducido directamente del inglés y de la edición citada por los autores.
} 
'símiles' o 'iguales' en algún aspecto - a saber, como competidores o rivales en el mismo juego (de la política democrática). Lo que está en juego aquí es la forma en que se perciben las posiciones relativas de los pocos y de la mayoría: si un segmento del pueblo percibe su situación como inferior o superior a la de otro segmento del mismo pueblo. Es por esto por lo que la envidia es diferente del odio. Odiamos a nuestros enemigos y no simplemente nos sentimos diferentes a ellos, sino también negados por ellos. Pero solamente envidiamos a aquellos que son suficientemente parecidos a nosotros para ser percibidos como un tipo de rivales o competidores. A diferencia de la enemistad, entonces, la rivalidad del resentimiento presupone identificación.

Por tanto, el resentimiento implica cierto grado de identificación, y parte de esta identificación está dada por los límites normativos que definen a la comunidad. En otras palabras, a menudo el resentimiento estará relacionado con la identificación y protección de ciertas normas que regulan nuestras relaciones sociales y políticas - en particular, en el caso del populismo, con los principios democráticos de igual reconocimiento y respeto-, y, por tanto, será sensible a la cuestión de la percepción de justicia de una situación. Sentimos resentimiento por la (percepción de) violación de las normas de justicia; sentimos resentimiento por los daños cometidos y sufridos en nosotros como resultado de esta violación; y sentimos resentimiento contra aquellos a quienes consideramos responsables de la violación. Sin embargo, la pregunta por el merecimiento (equidad, justicia) de la situación a los ojos del sujeto se plantea diferente según la emoción en cuestión. La indignación surge de una preocupación moral general por la justicia, ante la negación de derechos morales o el incumplimiento de las obligaciones que constituyen nuestras relaciones con otros agentes. Esta referencia a un marco normativo compartido, que está presente en casos de indignación, parece estar ausente en el caso de la envidia. Aristóteles, por su parte, parece descartar cualquier noción de 
justificación, garantías, méritos o merecimiento de su explicación de la envidia, que la define como 'un pesar por la abundancia evidente de los bienes dichos, sentido contra iguales, no porque algo le afecte a uno, sino por causa de ellos' (Aristóteles, 1971: 122). La envidia por la fortuna de otros no solo opera independientemente del modo en que los otros actúan o nos juzgan, pero también sin consideración por las expectativas de adquirir el bien para uno mismo - es suficiente que se le prive al otro. Este tipo de envidia es muy problemático a nivel político porque puede generar heridas universales o un agravamiento de las heridas sociales que afectan a aquellos que sienten envidia. Se puede pensar, por ejemplo, en aquellos casos en que ciudadanos de clases sociales bajas se oponen enérgicamente a políticas públicas que buscan poner balance en la igualdad social y económica, y de las que posiblemente ellos se beneficiarían (Cramer, 2016). Es probable que sientan que no reciben lo que consideran justo. No obstante, el sentimiento de que otros no merecen aquello puede convertirse en la motivación política principal. Hemos mencionado la noción de merecimiento. En efecto, Aristóteles, al menos implícitamente, pareciera pensar que incluso la envidia podría no ser enteramente inmune a cuestiones de 'merecimiento personal', es decir, a reivindicaciones que se sostienen en la percepción personal acerca del valor propio ('la parte justa' que corresponde a cada cual). Él afirma que las personas sienten envidia particularmente por 'aquello que le excita a uno o cree que debe tenerlo' (Aristóteles, 1971: 123). Sin embargo, existe una diferencia en las formas en que la indignación y la envidia se relacionan a las normas. Mientras que lo que subyace a la indignación es una preocupación moral general por la justicia; la preocupación, en el caso de la envidia, es personal y particular por lo que consideramos nuestra inferioridad no merecida.

Pero, aun si la envidia puede conllevar un mínimo de resentimiento, entendido como una emoción 'moral', el resentimiento no implica necesariamente comparación alguna. Es decir, el resentimiento puede ser 
sensible a la pregunta normativa acerca de la justicia de la situación del sujeto al tiempo que ignora la cuestión de la posición relativa percibida del sujeto y el objeto. Podemos, por tanto, sentir resentimiento con otros por considerar que nos causaron un agravio injusta e intencionadamente, sin compararnos con ellos o considerar que se benefician de una buena fortuna no merecida. Teniendo en mente estas distintas formas de resentimiento, es momento de pasar a una discusión acerca de cómo estas iluminan el fenómeno del populismo.

\section{El populismo reexaminado}

A pesar de que afirmamos que la lógica del populismo es una lógica del resentimiento, no todas las sub-lógicas del resentimiento son populistas. La lógica populista del resentimiento se mueve en un espacio entre la pura indignación y la envidia radical. Esto quiere decir que debe incluir ciertos elementos simultáneamente: un elemento normativo, a saber, una referencia a normas democráticas, en particular al compromiso superior de la democracia con la igualdad y la soberanía popular o a la idea del pueblo como el fundamento de la legitimidad política (Morgan, 1989); un elemento comparativo enmarcado en esa normatividad, a saber, un sentimiento de inferioridad no merecida; una rivalidad entre las partes, en la que, a la luz de compromisos compartidos, una parte es considerada responsable de - o culpable por- la inferioridad no merecida del otro; un llamado a la restauración de la igualdad democrática realizado por una parte en nombre del todo - 'el pueblo', de ahí el -ismo, populismo.

Como tal, la pura indignación frente a la violación de normas y principios democráticos -o lo que a muchas veces se denomina resentimiento 'moral' - no constituye en sí misma una base para el populismo. Es posible sentir resentimiento por la percepción de la violación de aquellas normas 
sin percibir que nosotros ni nuestro grupo haya sido afectado directamente, es decir, sin que dicha violación nos haya puesto en una posición de inferioridad no merecida. Un caso que ilustra este punto sería la oposición blanca al apartheid segregacionista en el régimen de Sudáfrica. Ellos se sentían ofendidos y sentían resentimiento por la violación de las normas democráticas de justicia en su comunidad política, aun cuando no se percibían a sí mismos como confinados en una posición de inferioridad no merecida debido a esta violación (en efecto, ellos estaban muy conscientes de los privilegios obtenidos). Por tanto, su acción política no se enmarca en el ámbito del populismo. De manera similar, los movimientos sociales motivados por la indignación frente a la violación de normas y principios democráticos, donde esto envuelve la inferiorización generada por esta negación, no son necesariamente populistas. Se puede pensar, por ejemplo, en movimientos como Black Lives Matter. Tanto los aspectos normativos como los de inferioridad no merecida están allí presentes; pero, en lugar de reivindicaciones de la parte en nombre del todo ('el pueblo'), estas contemplan principalmente el reconocimiento de la parte en su diferencia por parte de la otra parte. Nuestra definición del populismo como una lógica, que es principalmente una lógica de acción sociopolítica, nos permite también ver con mayor claridad por qué el populismo no puede ser identificado con ningún contenido ideológico. Una buena ilustración es el marxismo. Pese a que el marxismo postula que la lucha de clases es el motor de la historia, ambas partes — capitalistas y trabajadores - son considerados víctimas del mismo sistema: el capitalismo. Como tal, el marxismo está relacionado con el resentimiento frente a las inequidades sistémicas, pero, en tanto reconoce su naturaleza estructural, libera en último término a los agentes de responsabilidad y culpa. Su impulso no es un impulso moralizante. Sin embargo, este no es el caso de los movimientos Latinoamericanos que pertenecen al llamado 'Socialismo del Siglo XXI'. Sus intentos de movilización política a menudo se sustentan en el 
resentimiento hacia las actitudes e intenciones de los presuntos autores del sufrimiento de los trabajadores. Sus acciones no expresan mera frustración o malestar, pero incluyen la imputación de responsabilidad. El fundamento de sus reivindicaciones no es la clase social, sino la soberanía popular — de ahí que se realicen en nombre del 'pueblo'. Esto los coloca firmemente dentro del populismo.

Una vez que se examina la lógica que define al populismo, es fácil observar por qué el populismo se mantiene como un fenómeno ambiguo, al igual que las razones por las que su relación con la democracia es tan controvertida. El populismo puede tener tanto un rol preventivo como uno restaurador dentro de la democracia. Esta implica autogobierno y cierto grado de resentimiento contra el estar gobernado por alguien más. A nivel preventivo, el resentimiento hacia la elite gobernante, y la amenaza de conflicto que esto implica, podría operar en contra de la tendencia de las élites a transformar su poder e influencia desproporcional en una total indiferencia frente a los intereses de otros grupos y frente al bien común. Entendido como indignación, el populismo guarda una cercana relación con los principios y valores esenciales que fundamentan a la democracia, en particular, sus compromisos igualitarios. A nivel restaurador, por tanto, el populismo podría señalar cualquier violación y dirigirse a la comunidad en general con vistas a la restauración de compromisos compartidos y promesas incumplidas. Es por ello por lo que a menudo vemos al populismo como sintomático de importantes exclusiones democráticas que se pasan por alto y con las que no se lidia. Los estallidos populistas aparecen regularmente en la externalización de la frustración, exasperación o ira frente a la experiencia vivida de exclusiones.

En la medida en que el populismo se relaciona con un fundus normativo, y que moviliza a los ciudadanos en torno a su violación, este tiene el potencial para un despertar democrático. Este potencial, no obstante, no necesariamente se cumple. El resentimiento es notoriamente 
una lógica voluble, difusa y escurridiza. En su extremo, esta podría fijarse obsesivamente en objetos particulares, o tornarse en una cuestión sin un objeto particular y totalmente abarcadora. Como resultado, la comprensión de qué es lo que provoca la pérdida o las heridas podría verse comprometida. Siempre existe la oportunidad de que las demandas populistas despierten e involucren a la comunidad en una discusión acerca de qué es lo que mejor restauraría y protegería las normas y principios que se descubrieron transgredidos. Pero también existe la posibilidad de que simplemente se bloquee esta discusión. Este cierre puede ocurrir de dos maneras que se refuerzan mutuamente. En primer lugar, el problema en cuestión -es decir, las causas de la injusticia colectiva o sistémica enfrentada, e incluso su alcance- se presta a diagnósticos errados cuando se fija la atención en una simple 'causa' o cuando todas las causas posibles pueden ser $l a$ causa. En segundo lugar, un problema mal diagnosticado puede prestarse a soluciones que están disponibles inmediatamente o a una solución redentora que pretenda abarcarlo todo. Cualquier consideración del cómo y el porqué un problema pudo haber sido mal diagnosticado - o de cómo y por qué incluso ideales acordados pueden implicar distintos modos de interpretación e implementación, y de encontrar oposición dentro de una democracia política - es potencialmente descartable.

El populismo nunca es meramente acerca de un resentimiento moral. No es mera frustración por la violación de un fundus normativo o por las injusticias sistémicas derivadas. Establece, asimismo, una relación conflictiva entre grupos rivales en la medida en que se imputa responsabilidad e incluso culpa por dichas violaciones a ciertos actores y acciones. Esta disposición populista hacia la moralización y la imputación de culpa inevitablemente abre las puertas a riesgos. Esto tiende a retratar la política como un juego de suma cero, donde las ganancias del otro necesariamente son mis pérdidas. Cuando la indignación se convierte en envidia, la cooperación social se vuelve difícil, y la referencia normativa 
residual que caracteriza a la envidia pasa apuros al tener que dirigirse a la comunidad en general y, en particular, a los que se percibe como transgresores. A diferencia de la indignación, la envidia es dolorosa y no constructiva. ¿Cómo puede la mayoría cooperar con la minoría, o una parte de la mayoría dirigirse a otra parte dentro de ella, si no hay deseo de que la minoría o la otra parte tenga algún bien, incluso si ellos mismos no lo desean, incluso si ellos prefieren privar a otros del bien para adquirirlo para sí mismos, incluso si la minoría o la otra parte no les causa ningún daño? Centrarse exclusivamente en la envidia, en la comparación de fortunas, $\mathrm{y}$ en acciones y agentes supuestamente culpables intencionalmente, puede sacrificar la política progresista en manos de la pasivización de la victimización. Puede fácilmente distraer de, o hasta excluir el lidiar con, las desigualdades colectivas y sistémicas que podrían estar detrás de las heridas sentidas y del tipo de política que les da forma. Tal como Michael Ure (2015: 608) explica acertadamente, 'dado que el resentimiento sociopolítico', al identificar y abordar injusticias colectivas y sistemáticas, 'responde a la regulación política de riesgos y contingencias ontológicas básicas —desgracia, irreversibilidad, pérdida, etc.—, este corre el riesgo de devenir en un ressentiment ontológico', una forma de envidia radical u odio lleno de envidia, ' $y$, con ello, en un culpar incesante e indiscriminado, en un despojo lleno de envidia de lo bueno, y en intentos peligrosos por hacer de la política el locus de redención metafísica'. Esta envidia radical es particularmente peligrosa porque puede obsesionarse con las ganancias marginales más nimias y, así, socavar aún más las posibilidades de confianza y cooperación. Como Raymond Geuss (2016: 183) explica, la envidia radical puede iniciar "un ciclo diabólico en el cual la envidia se enfoca en ventajas cada vez menores, y se vuelve tentador pensar que el remedio para todos los defectos es la búsqueda de otras dimensiones de la vida que aún no han sido "igualadas"'. En ese punto, cualquier visión de 
política progresista puede convertirse en una distopía de perfeccionismo igualitario o en monismo.

Mientras que la indignación puede estar dirigida hacia objetos abstractos (la violación de las normas de justicia, por ejemplo) y hacia actores distantes, la envidia normalmente se dirige hacia nuestros vecinos —o conciudadanos, aquellos que están cerca de nosotros. Esto, combinado con la naturaleza centrífuga de la envidia radical, hace que el límite que separa al resentimiento de la enemistad sea muy permeable. Los peligros de traspasar dicho límite fueron muy bien comprendidos por el populista de Minnesota, Ignatius Donnelly, en su novela distópica Caesar's Column (1960 [1892]). El término populismo aún no se había acuñado en inglés cuando Donnelly redactó la Plataforma del Partido Populista (1892) en Norteamérica. Él creía que sus esfuerzos literarios eran integral al proyecto político populista que concibió. Caesar's Column nos retrata una sociedad en la que hay un creciente sentimiento de pérdida de status y de control sobre los eventos que afectan a la vida de uno, que va acompañado con el desplazamiento concomitante - tanto en el país como en el extranjerode dicho control a las corporaciones, individuos ricos, y élites urbanas desinteresadas. Se acumulan resentimientos sin darles ninguna forma de tratamiento. Las soluciones sistémicas, como el marxismo, aparecen frustrantes y desalentadoras en medio de la creciente ira reprimida. El escenario es tal de una guerra civil inminente, de un sistema de gobierno en guerra con sí mismo. Aquí es donde el populismo, un compañero ambivalente de la democracia, conduce al democidio. 


\section{Referencias}

Abts, K. \& Rummen, S. (2007) Populism versus Democracy. Political Studies, 55: 402-24.

Arditi, B. (2010 [2007]) La Política en los Bordes del Liberalismo. Barcelona: Gedisa.

Aristóteles (1971) Retórica. Madrid: Instituto de Estudios Políticos

Aslanidis, P. (2015) Is populism an ideology? Political Studies 64: 1-16.

Barlabet, J. (1992) A macro sociology of emotion: class resentment. Sociological Theory 10: 150-163.

Bartels, L. (2016) Unequal Democracy. Princeton: Princeton University Press.

Betz, H-G. (2002) Conditions favouring the success and failure of radical rightwing populist parties in contemporary democracies. In: Mény, Y. \& Surel, Y. (eds.) Democracies and the Populist Challenge. Basingstoke: Palgrave Macmillan: 197-213.

Bonikowski, B. \& Gidron, N. (2014) The populist style in American politics: presidential campaign discourse, 1952-1996. Social Forces 94: 1593-621.

Brubaker, R. (2017) Why populism? Theory and Society 46(5): 357-85.

Canovan, M. (1981) Populism. London: Junction Books.

Canovan, M. (1999) Trust the people! Populism and the two faces of democracy. Political Studies 47: 2-16.

Canovan, M. (2002) Taking politics to the people. In: Mény, Y. \& Surel, Y. (eds.) Democracies and the Populist Challenge. Basingstoke: Palgrave Macmillan: 25-44.

Canovan, M. (2004) Populism for political theorists? Journal of Political Ideologies 9(3): 241-52.

Cramer, K. (2016) The Politics of Resentment. Chicago: University of Chicago Press. 
Demertzis, N. (2006) Emotions and populism. En: Clarke, S. et al. (eds) Emotions, Politics and Society. Basingstoke: Palgrave Macmillan: 103-22.

Donnelly, I. (1960 [1892]) Caesar's Column: A Story of the Twentieth Century. Cambridge: Harvard University Press.

Engels, J. (2015) The Politics of Resentment. A Genealogy. Pensilvania: Penn State University Press.

Fenton, S. (2012) Resentment, class and social sentiments about the nation. Ethnicities 12: 465-83.

Fraser, N. (1999) Repensando la Esfera Pública. Ecuador Debate 46: 139-174.

Garsten, B. (2012) Being represented. Manuscrito no publicado presentado en marzo en el Stanford Political Theory Workshop.

Germani, G. (2003 [1978]) Autoritarismo, Fascismo y Populismo Nacional. Buenos Aires: Temas.

Gest, J. (2016) The New Minority. Oxford: Oxford University Press.

Gest, J. \& Gray, S. (2015) Silent Citizenship: the politics of marginality in unequal democracies. Citizenship Studies 19: 465-73.

Geuss, R. (2015) Reality and Its Dreams. Cambridge: Cambridge University Press.

Green, J. (2015) Solace for the frustrations of silent citizenship: the case of Epicureanism. Citizenship Studies 19: 492-506.

Howarth, D. \& Stavrakakis, Y. (2000) Introducing discourse theory and political analysis. En: Howarth, D. et al. (eds.) Discourse Theory and Political Analysis. Manchester: Manchester University Press: 1-23.

Jansen, R. (2011) Populist mobilization. Sociological Theory 29: 75-96.

Kaase, M. (2007) Perspectives on political participation. En: Dalton, R. \& Klingemann, H-D. (eds.) The Oxford Handbook of Political Behaviour. Oxford: Oxford University Press: 784-96.

Kazin, M. (1995) The Populist Persuasion. New York: Basic Books.

Laclau, E. (1999) Politics, polemics and academics: an interview by Paul Bowman. Parallax 5: 93-107. 
Laclau, E. (2005) La Razón Populista. Buenos Aires: Fondo de Cultura Económica. Laclau, E. (2009 [2005]) Populismo: ¿Qué nos dice el nombre? En: Panizza, F. (comp.) El Populismo como Espejo de la Democracia. Buenos Aires: Fondo de Cultura Económica: 51-70.

Laclau, E. \& Mouffe, C. (1987) Hegemonía y Estrategia Socialista. Madrid: Siglo XXI.

Lefort, C. (1988) Democracy and Political Theory. Minneapolis: University of Minnesota Press.

Minogue, K. (1974 [1969]) Populism as a political movement. En: Ionescu, G. \& Gellner, E. (eds.) Populism: Its Meanings and National Characteristics. London: Weidenfeld \& Nicolson: 197-211.

Moffitt, B. (2015) How to perform crisis: a model for understanding the key role of crisis in contemporary populism. Government and Opposition 50: 189-217.

Moffitt, B. and Tormey, S. (2014) Rethinking populism: politics, mediatisation and political style. Political Studies 62: 381-97.

Morgan, E. (1989) Inventing the People: The Rise of Popular Sovereignty in England and America. New York: W. W. Norton \& Company.

Mudde, C. (2004) The Populist Zeitgeist. Government and Opposition 50: 189-217.

Mudde, C. (2007) Populist Radical Right Parties in Europe. Cambridge: Cambridge University Press.

Müller, J. W. (2016) What is Populism? Pensilvania: Penn State University Press.

Pauwels, T. (2011) Measuring populism. Journal of Elections, Public Opinion and Parties 21: 97-119.

Rosanvallon, P. (2007) La Contrademocracia: La política en la Era de la Desconfianza. Buenos Aires: Manantial.

Shils, E. (1956) The Torment of Secrecy: The Background and Consequences of American Security Policies. London: Heinemann.

Schmitt, C. (1991 [1927]) El Concepto de lo Político. Madrid: Alianza Editorial.

Torfing, J. (1995) New Theories of Discourse. Oxford: Blackwell.

Urbinati, N. (2014) Democracy Disfigured. Cambridge: Harvard University Press. 
Ure, M. (2015) Resentment/ressentiment. Constellations 22: 599-613.

Weyland, K. (2001) Clarifying a contested concept. Comparative Politics 34: 1-22.

Wiles, P. (1974 [1969]) A syndrome, not a doctrine: some elementary theses on populism. En: Ionescu G \& Gellner E (eds.) Populism: Its Meanings and National Characteristics. London: Weidenfeld \& Nicolson: 166-79.

Worsley, P. (1974 [1969]) The concept of populism. En: Ionescu, G. \& Gellner, E. (eds.) Populism: Its Meanings and National Characteristics. London: Weidenfeld \& Nicolson: 212-50. 